\title{
Glucose-6-phosphate dehydrogenase Aveiro: a de novo mutation associated with chronic nonspherocytic hemolytic anemia
}

\author{
Elísio Costa, José Manuel Cabeda, Emilia Vieira, Rui Pinto, Susana Aires Pereira, Leonor Ferraz, Rosário Santos, and José Barbot
}

\begin{abstract}
Glucose-6-phosphate dehydrogenase (G6PD) deficiency is a common X-linked enzyme abnormality. The clinical phenotype is variable but often predictable from the molecular lesion. Class I variants (the most severe forms of the disease) cluster within exon 10 , in a region that, at the protein level, is believed to be involved in
\end{abstract}

dimerization. Here we describe a de novo mutation (C269Y) of a new class I variant (G6PD Aveiro) that maps to exon 8. Mutant and normal alleles were found in both hematopoietic and buccal cells, indicating the presence of mosaicism. The available model of the protein predicts that this lesion lies in proximity to the dimer interface of the molecule. A possible mechanism to explain the severity of the defect is proposed. (Blood. 2000;95:14991501)

(ㄷ) 2000 by The American Society of Hematology

\section{Introduction}

Chronic nonspherocytic hemolytic anemia (CNSHA) is the most severe and rare form of glucose-6-phosphate dehydrogenase (G6PD) deficiency. ${ }^{1}$ Patients have lifelong chronic hemolytic anemia accompanied by episodes of acute crises triggered by infections or the ingestion of certain drugs. ${ }^{1}$ These mutant variants of G6PD appear in all populations, albeit at a low frequency. Curiously, the same variant may be found recurrently and independently in persons unlikely to be ancestrally related., ${ }^{2,3}$

To date, 57 different mutations causing CNSHA have been identified, ${ }^{2,4}$ most of which are missense mutations resulting in single amino acid substitutions. Although they are spread throughout the coding region, there is a major cluster (25 mutations) located in exon 10 and a minor cluster near exons 7 and 8.2,4 These mutations map within or in proximity to the dimer interface region of the molecule, suggesting that the severity of the disease is the result of an impaired ability to form stable dimers. ${ }^{5}$

We describe a boy born in Aveiro, Portugal, with severe chronic hemolytic anemia present at birth. The clinical picture was attributed to undetectable G6PD activity. Genetic studies revealed a new C269Y mutation, which was present in the patient but could not be detected in his mother or sister.

\section{Study design}

Patient

The patient is a 5-year-old boy from Aveiro, Portugal, born to healthy, nonconsanguineous parents with no known family history of anemia. He had chronic hemolytic anemia since birth (hemoglobin between 7.1 and 9.8 $\mathrm{g} / \mathrm{dL}$ ) and underwent exchange blood transfusion in the immediate neonatal period. His clinical history includes 6 episodes of severe acute intravascular hemolysis that required hospitalization and erythrocyte transfusion. On physical examination, his spleen was palpable $6 \mathrm{~cm}$ below the left costal margin. Except for anemia, he has had normal health and development.

\section{Enzyme analysis}

G6PD activity was assayed according to the recommendations of the World Health Organization. ${ }^{6}$ To assay the enzyme activity on granulocytes, these cells were purified after centrifugation on a double-density gradient (Histopaque 1119 and 1077; Sigma, St Louis, MO). The cytochemical test was performed according to the procedures described by Dacie and Lewis. ${ }^{7}$

\section{DNA analysis}

Polymerase chain reaction amplification and single strand conformational polymorphism (SSCP) analysis were performed as previously described..$^{89}$ Sequencing was carried out on newly generated amplicons of fragments that had revealed aberrant conformers. The respective forward and reverse primers were used in independent sequencing reactions. Chromosome X-linked microsatellite markers DXS548, ${ }^{10}$ STR44, STR45, STR49, and STR $50^{11}$ were analyzed by capillary electrophoresis using fluorochromelabeled primers.

\section{Results and discussion}

The diagnosis of G6PD deficiency was based on an undetectable G6PD activity in spite of reticulocytosis (30\%). The patient's

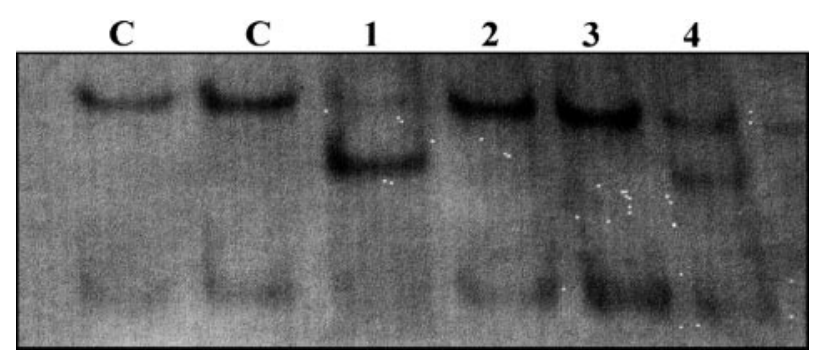

Figure 1. SSCP analysis of G6PD exon 8. Results obtained with hematopoietic cells of the patient, mother and sister (lanes 1, 2 and 3, respectively) and with the patient's buccal cells (lane 4).
From the Serviço de Hematologia Clínica, Hospital de Crianças Maria Pia, Porto; the Serviço de Hematologia Clínica, Hospital Geral de Santo António, Porto; the Unidade de Genética Molecular do Instituto de Genética Médica Doutor Jacinto de Magalhães, Porto; the Departamento Materno-Infantil, Centro Hospitalar de Vila Nova de Gaia, Vila Nova de Gaia, Portugal.

Submitted July 6, 1999; accepted October 5, 1999.
Reprints: Elísio Costa, Serviço de Hematologia, Hospital de Crianças Maria Pia, Rua da Boavista 827, 4050-1-466 Porto, Portugal; e-mail: mp354@mail.telepac.pt.

The publication costs of this article were defrayed in part by page charge payment. Therefore, and solely to indicate this fact, this article is hereby marked "advertisement" in accordance with 18 U.S.C. section 1734.

(C) 2000 by The American Society of Hematology 
Figure 2. Extract of direct sequencing of exon 8. (A) Normal sequencing histogram. (B) Patient's peripheral blood histogram with a small G peak. (C) Patient's buccal cell histogram with a normal $G$ peak greater than a mutated A peak.

mother showed a normal enzymatic activity (105\%) and no evidence of deficient cells in the cytochemical test (methemoglobin elution test). Biochemical characterization of the mutant G6PD was not feasible because of the total absence of enzymatic activity. The same was true when granulocyte cells were used as the patient enzyme source.

After screening for known mutations by differential endonuclease restriction, SSCP analysis of the patient's G6PD gene showed a mobility shift in exon 8 (Figure 1). Sequencing revealed that this was a $\mathrm{G}$ to $\mathrm{A}$ transition at nucleotide 806 (Figure 2), resulting in a cysteine-to-tyrosine change at amino acid 269 . The entire coding region was later sequenced, but no further alteration was detected. Close analysis of the sequencing histogram revealed a small but visible $G$ peak at the mutation site. This mosaicism was later confirmed by sequencing and SSCP analysis of the patient's buccal cells, which again revealed the presence of 2 cell populations (Figures 1 and 2).

The C269Y mutation was not found in the patient's mother and sister, in whom both hematopoietic and buccal cell samples were analyzed. Haplotyping using X-linked markers confirmed the mother-child relationships. The G6PD intragenic markers were not informative, but the patient and his sister were found to have inherited the same maternal allele for the FRAXA marker DXS548, which maps nearby. This, together with the evidence of mosaicism in the patient, suggests a de novo mutational event that must have occurred during a very early stage of embryogenesis. ${ }^{12}$

Most class I mutations are located in exon 10, in an area believed to be involved in dimerization. ${ }^{5}$ The variant described in this report, G6PD Aveiro, results from a mutation in exon 8, close to a minor cluster of known CNSHA mutations. ${ }^{2}$ It is difficult to predict the conformational changes brought about by this C269Y mutation. However, based on the preliminary model proposed by Naylor et al, ${ }^{5}$ it may be speculated that this variant behaves in a manner analogous to G6PD Corum (E274K). The class I phenotype of the latter is thought to result from the disruption of a dimer-stabilizing salt bridge normally formed between Glu274 and Arg348. Because Glu274 is at the end of the alpha helix $\alpha \mathrm{i}$, where Cys269 is located, and considering the general rule that there are 3.6 amino acids per alphahelix turn, these 2 residues are expected to be spatially close. As such, the constraints on the orientation of the alpha helix imposed by the substitution of the small side chain of Cys by the large one of Tyr in G6PD Aveiro could be expected to change the spatial position of Glu274, thereby impairing the formation of the above-mentioned salt bridge. The resultant dimer instability could then explain the severe clinical picture observed in our patient. A recent report by $\mathrm{Au}$ et $\mathrm{al}^{13}$ reports further advances in the elucidation of the G6PD crystal structure. However, the reported data are so far insufficient to evaluate our model. Therefore, validation of this proposed mechanism requires further experimental data on the 3-dimensional structure of human G6PD.

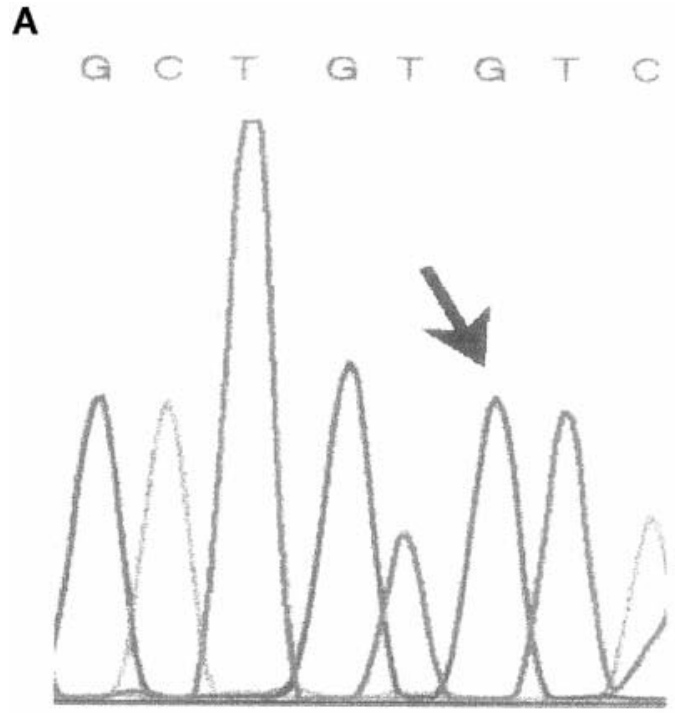

B

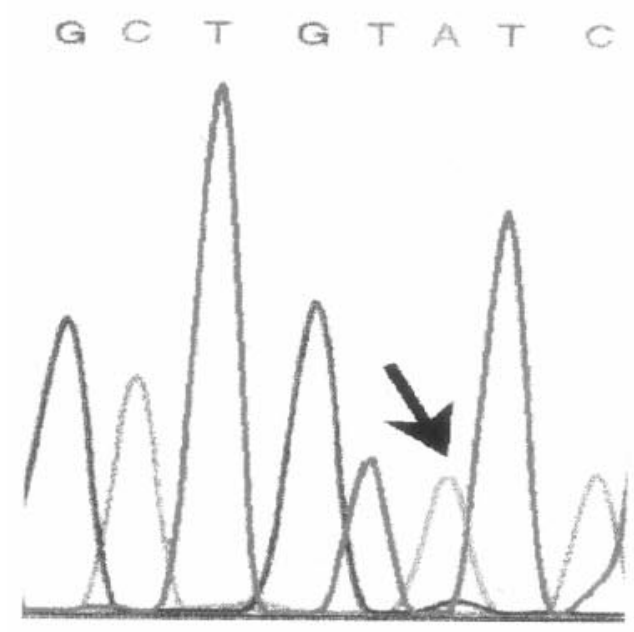

C
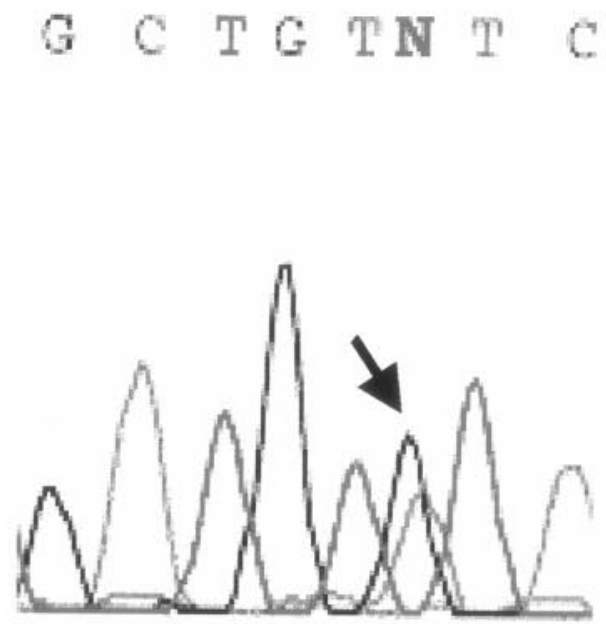


\section{References}

1. Luzzatto L. Glucose-6-phosphate dehydrogenase deficiency and hemolytic anemia. In: Nathan DG, Oski FA, eds. Hematology of Infancy and Childhood. Vol. 1. Philadelphia: WB Saunders; 1998: 704 .

2. Vulliamy TJ, Kaeda JS, Ait-Chafa D, et al. Clinica and haematological consequences of recurrent G6PD mutations and a single new mutation causing chronic nonspherocytic haemolytic anaemia. Br J Haematol. 1998;101:670-675.

3. Mason PJ, Sonati MF, MacDonald D, et al. New glucose-6-phosphate dehydrogenase mutations associated with chronic anemia. Blood. 1995;85: 1377-1380.

4. Vulliamy TJ, Luzzatto L, Hirono A, Beutler E. Hematologically important mutations: glucose-6phosphate dehydrogenase. Blood Cells Mol Dis 1997;23:302-313.

5. Naylor CE, Rowland P, Basak AK, et al. Glucose- 6-phosphate dehydrogenase mutations causing enzyme deficiency in a model of the tertiary structure of the human enzyme. Blood. 1996;87:29742982.

6. Betke K, Brewer GJ, Kirkman HN, et al. Standardization of the procedures for the study of G6PD: report of a WHO scientific group. World Health Organ Tech Rep Ser. 1967:366.

7. Dacie JV, Lewis SM. Practical Haematology. Edinburgh: Churchill Livingstone; 1991.

8. Orita M, Suzuki Y, Sekiya T, Hayashi K. Rapid and sensitive detection of point mutations and DNA polymorphisms using the polymerase chain reaction. Genomics. 1989;5:874-879.

9. Calabro V, Mason PJ, Civitelli D, et al. Genetic heterogeneity at the glucose-6-phosphate dehydrogenase locus in southern Italy: a study on a population from the cosenza district. Am J Hum Genet. 1993;52:527-536.
10. Verkerk AJMH, Pieretti M, Sutcliffe JS, et al. Identification of a gene (FMR1) containing a CGG repeat coincident with a breakpoint cluster region exhibiting length variation in fragile $X$ syndrome. Cell. 1991;65:905-914.

11. Clemens PR, Fenwick RG, Chamberlain JS, et al. Carrier detection and prenatal diagnosis in Duchenne and Becker muscular dystrophy families using dinucloetide repeat polymorphisms. Am J Hum Genet. 1991;49:951-960.

12. Zimmerman SA, Ware RE, Forman L, Westwood B, Beutler E. Glucose-6-phosphate dehydrogenase Durham: a de novo mutation associated with chronic hemolytic anemia. J Pediatr. 1997; 131:284-287.

13. Au SWN, Naylor CE, Gover S, et al. Solution of the structure of tetrameric human glucose-6phosphate dehydrogenase by molecular replacement. Acta Cryst. 1999;D55:826-834. 